\title{
Non-traditional Economic Estimation of Dairy Cow Income in Grazing Systems
}

\author{
P. R. Marini ${ }^{1,2,4}$, R. Fernández ${ }^{3}$ \& R. J. Di Masso ${ }^{2,4}$ \\ ${ }^{1}$ Facultad de Ciencias Veterinarias, Cátedra de Producción de Bovinos Lecheros, Universidad Nacional de \\ Rosario (UNR), Argentina \\ ${ }^{2}$ Carrera del Investigador Científico (CIC)-Universidad Nacional de Rosario (UNR), Argentina \\ ${ }^{3}$ Cátedra de Economía Agraria y Legislación Rural, Facultad de Ciencias Veterinarias, Universidad Nacional de \\ Rosario (UNR), Argentina \\ ${ }^{4}$ Centro Latinoamericano de Estudios de Problemáticas Lecheras (CLEPL), Facultad de Ciencias Veterinarias, \\ Universidad Nacional de Rosario (UNR), Argentina \\ Correspondence: Marini, P. R., Facultad de Ciencias Veterinarias, Universidad Nacional de Rosario, Ovidio Lagos \\ y Ruta 33, Casilda (2170), Santa Fe, Argentina. E-mail: pmarini@unr.edu.ar
}

Received: April 5, 2018 Accepted: April 19, 2018 Online Published: May 4, 2018

doi:10.5539/sar.v7n3p21 URL: https://doi.org/10.5539/sar.v7n3p21

\begin{abstract}
The objective was to evaluate the economic efficiency of two groups of cows in a grazing system using a non-traditional estimation strategy. Retrospective data were used corresponding to the lactations of 216 primiparous and multiparous cows of Holstein breed American-Canadian biotype with records of all their productive life, from their incorporation to the system until their sale or death, collected between the years 1992-2012. It was concluded that the economic efficiency of the two groups of cows analyzed is not only determined by milk production, but by a set of additional variables such as longevity and reproduction.
\end{abstract}

Keywords: milk production, reproduction, longevity, efficiency

\section{Introduction}

Considering the rentability of the business seems something logical for any enterprise regardless its final product, since that allows knowing how efficient it is in all its aspects and, besides, to make the right decisions on time. However, in the milking business this is not so and producers give privilege to short-term profit related to a higher milk production rather than to the stability and sustainability of the business associated to aspects such as the sale of surplus heifers, the sale of males, the lower percentage of discard, the less use of technology in supplies, and others.

The milking industry in Argentina has shown a productive stagnation close to 11,000,000 liters per year since 2011. These liters are produced in farms whose number has remained rather stable varying from 11,282 in the year 2011 (Sánchez et al., 2012) to 11,500 productive units estimated in the year 2016 (Bargo, 2016). The poor growth in the Argentinian industry between 2011 and 2015 happened within a context of relative good prices both of milk and of a key supply such as maize. In this scenario, there would seem that the problems related to the growth of the national milking industry are related mainly to the performance of the farms, which are facing trouble increasing their production levels, even under auspicious economic conditions (Pace Guerrero and Gastaldi, 2016). Even though it might not be the only way to take, Galli et al., (2017), working in a group of farms in the south of the province of Santa Fe, have shown that there are concrete possibilities of improving their systems of production through the application of technology of processes based on planning and managing the available resources.

In most dairy establishments, producers ignore their productive rate, their production costs and the economic result of their cattle business and of other branches of the business. For that reason, they can hardly make the proper decisions to improve their results (Ferrada Neira, 2004). Facing the urgent need to increase the technical and economic efficiency of the milking production systems, the determination of other indicators represent a highly important tool, since they are essential to determine the productivity of the herd. At the same time, it is necessary and decisive to make an analysis of the higher production costs that the market demands, in order to 
evaluate the rentability of the herd and to secure their future maintenance. This reflection is rooted in Camargo's (2012) statement, that there is an imposition of increasing cow productivity as the only way out, which necessarily derives in an increase in production costs, including hand labor and those deriving from land as a productive resource. In coincidence with reports from Horn et al., (2012), a reduction in the yield of milk production does not necessarily lead to lower profits, if it is accompanied by an increase in cow longevity. According to Stott (1994), the economic advantage of longevity lies primarily in retaining productive cows for as long as possible, while ensuring that less productive cows are replaced as soon as it is economic to do so. In this context, the aim of this work was to evaluate the economic efficiency of the two groups of Holstein cows in a grazing system using a non-traditional estimation strategy

\section{Materials and Methods}

Retrospective data were used corresponding to the lactations of 216 primiparous and multiparous cows of Holstein breed of American-Canadian biotype with records of all their productive life -from their incorporation to the system until their sale or death- collected between the years 1992-2012, in the farm belonging to the agro-technical school Gral. San Martín, belonging to the National University of Rosario. The farm is located in the city of Casilda, province of Santa Fe, Argentina ( $33^{\circ} 02^{\prime} 39^{\prime \prime}$ south latitude, $61^{\circ} 10^{\prime} 05^{\prime \prime}$ west longitude). It has milk control of the Rural Society of Totoras, Oficial Entity $\mathrm{N}^{\circ} 13$, and exhibits the following characteristics: (1) only Holstein cows are used; (2) food is basically pastures (alfalfa) with supplementation (maize grain, maize silos and rolls) supplied in different proportions according to the seasonal availability of the alfalfa meadows; (3) regular gynecological controls are carried out; (4) there is an official milking control; (5) it is free from tuberculosis, campylobacteriosis and trichomoniasis, in control of leptospirosis, bovine infectious rhinotracheitis and bovine viral diarrhea; (7) cows are artificially inseminated with semen from American or Canadian origin and (8) available data are reliable. These characteristics guarantee minimum standards of health and food managing and technical support, which places this farm above the average in the area, in these aspects.

In the period when the data were collected, cows were handled in the same milking facilities. Animals were divided into two categories: pure cows (PC) $(n=88)$ and cows with breed records $(\mathrm{CBR})(\mathrm{n}=128)$. The difference between both is based on the fact that the formers are inseminated with semen from tested bulls while such a practice is not kept constantly in the case of the laters. In order to achieve the condition of pure cow, seven generations of tested progenitors are needed, which implies that the members of the group of cows with breed records are in different stages of that way to attain it. During the evaluated period, cows consumed forages under direct gazing (consociated pastures, and annual winter and summer pastures) or conserved (maize and sorghum silos, pasture hay) and concentrated (maize and sorghum grains). The weather was not uniform during the study, both as regards rainfalls as well as combinations of temperature and relative humidity.

Each cow belonging to each of the two above mentioned groups was characterized according to the values of two reproductive indicators: age at first delivery in days (EPP) and first delivery-delivery interval in days (IPP) and two productive indicators: milk production adjusted to 305-day lactation yield in liters (PL) and butyrose fat produced in kilograms (GB). Even though the quantity of butyrose fat and the quantity of milk are closely related, both indicators were included because the first one does not refer to real values but to values adjusted to a time of lactation common to every individual (305 days), while the quantity of fat shows the kilograms of butyrose fat effectively produced throughout the whole productive life of the animal.

The whole behavior of the four indicators mentioned was evaluated with the multivariate technique of principal components. For the purpose of analysis, the principal components generated with such technique corresponding to each animal were treated as new random variables. Individual values corresponding to the first (PC1) and the second (PC2) principal component, were graphed in a system of orthogonal Cartesian axes. Four quadrants were defined through two perpendicular lines which intersect each of the axes in the medium values of such components. Quadrants were numbered correlatively from I to IV, anti-clockwise, starting from the top right quadrant. Next, the animals in each quadrant were identified, yielding four groups of cows (Quadrant I: high values for both components; Quadrant II: low values for PC1 and high values for PC2; Quadrant III: low values for both components and Quadrant IV: high values for PC1 and low values for PC2). At the same time, within each quadrant, cows were discriminated into pure or with breed records. The association between both categories (type of cow and quadrant of origin) was evaluated by means of Chi-square test. The quadrant effect on each of the productive and reproductive traits involved in the principal component analysis jointly with three indicators of cows' longevity (NP: numbers of deliveries registered throughout their reproductive life, IL: milk index, defined as milk production per day of life and calculated as the ratio between the total milk production in liters of a cow throughout its life and the number of days required for producing them, and IG: index of fat, defined as the production of butyrose fat per day of life and calculated as the ratio between the total production of butyrose 
fat in a cow's life in kilograms and the number of days required for producing them); was assessed by means of a one way analysis of variance followed by the Bonferroni test of multiple comparisons.

For the analysis of the economical balance, the following indicators were considered:

1. Pl total (litres): $\mathrm{pl} 305 * 100$

2. Births: estimation of births adjusted in a year according to Magnasco (1998).

3. Born female: births / 2 (rounding out to females)

4. \% loss: estimated in agreement with González Besteiro (2010)

5. Real females: born females $-8 \%$ of loss

6. Apt females: Females really apt for replenishing, estimating 24 months as the optimum (Bargo, 2016) expected value 100, as the values went further, it was calculated (value of epp of each group in months *100 / 24 months as the optimum value (Marini, 2016).

7. replacement: 100 cows / (np*100)

8. lack or surplus of cows: replacement - apt females

9. Milk: pl total * Price per liter paid to the producer. Price per liter paid to the producer $\$ 5.10$ (Liniers Market, 2017. https://www.mercadodeliniers.com.ar).

10. Discard cow: (weight of the discard cow* replacement) * Price of the kilogram of discard cow. Weight of the discard cow: $550 \mathrm{~kg}$. Price of the kilogram of discard cow \$18 (Liniers Market, 2017. https://www.mercadodeliniers.com.ar).

11. Calf: weight of the calf * price of the kilogram of calf. Weight of the calf: $80 \mathrm{~kg}$ when weaning. Price of the kilogram $\$ 35$ (Liniers Market, 2017. https://www.mercadodeliniers.com.ar).

12. Heifers: number of heifers * Price of the heifer $\$ 18000$ (Liniers Market, 2017 https://www.mercadodeliniers.com.ar).

13. Outflow: need to purchase in any category

14. Balance: Income (milk + discard + cow + calf + heifer $)-$ Outflow (heifer)

15. $\$ \mathbf{1}=\boldsymbol{€} \mathbf{2 4 , 7 2}$ (https://www.lanacion.com.ar/economia/divisas)

Finally, three situations were modelled with the solely variation of milk production (5000, 6500 and 8500 liters), remaining the values of the other traits identical for the three cases. For each of the three models the economic balance using only CI and CIV data were calculated. These two quadrants were chosen because CI represents cows typical of intensive systems while CIV represents cows from extensive grazing systems.

\section{Results}

The first principal component (PC1) explained the $35.12 \%$ of the phenotypic variance and was correlated in a positive and significant way $(\mathrm{P}<0.0001)$ with milk production $(\mathrm{r}=0.804)$ and fat production $(\mathrm{r}=0.544)$, in a negative way $(\mathrm{P}=0.004)$ with age at first delivery $(\mathrm{r}=-0.194)$ and positively $(\mathrm{P}<0.0001)$ with interval between deliveries. Therefore, it was named PRODUCTION.

The second principal component (PC2) explained $25.04 \%$ of the total variance and was correlated positively and significantly $(\mathrm{P}<0.0001)$ with age at first delivery $(\mathrm{r}=0.865)$ and with the interval delivery-delivery $(\mathrm{r}=0.317 ; \mathrm{P}$ $<0.0001)$, in a negative way $(\mathrm{P}<0,0001)$ with fat production $(\mathrm{r}=-0.313)$ and positively with milk production $(\mathrm{r}$ $=0.193 ; \mathrm{P}=0.005)$. Therefore, it was called PRECOCITY.

The distribution of pure cows and cows with breed records was not homogeneous $\left(X^{2}=17.8 ; P=0.0005\right)$ in the four quadrants. In the first quadrant, it is observed a little higher proportion of pure cows (27.5\%) than cows with breed records $(20.2 \%)$, same as in the fourth quadrant, where nevertheless the difference is bigger with $37.5 \%$ of total pure cows facing a $16.9 \%$ of cows with breed records. In the other two quadrants, there is a majority of cows with breed records particularly in the second quadrant with $41.1 \%$ versus $21.3 \%$ of pure cows. In the third quadrant the values are $24.2 \%$ versus $13.8 \%$ for cows with breed records and pure respectively.

Figure 1 resumes the values of productive indicators corresponding to both categories of cows, according to the quadrant they belong. It is observed that, within each quadrant, there are only significant differences between the categories of the cows $(\mathrm{p} \leq 0.05)$ as regards IL, IPG and IG in Quadrant I and as pl305 in Quadrant IV.

Table 2 presents the values derived from the proposed model of economic balance applied to cows of both categories belonging to Quadrants I and IV, both with high values of PC1 (PRODUCTION) and different value 
of PC2 (PRECOCITY). In it there can be observed that cows of Quadrant IV, independently from their category, pure or with breed records, generate bigger economic income than those from Quadrant I due to the fact that although cows from Quadrant IV generate lower incomes from milk production, they present higher incomes from the sales of heifers and calves.

Table 1. Productive-reproductive characterization of the two types of milking cows throughout their useful lives, discriminated according to the Quadrant they belong to, defined by the values of the first and second components, generated from a multivariate principal component analysis

\begin{tabular}{|c|c|c|c|c|c|c|c|}
\hline \multicolumn{3}{|c|}{ Quadrant II } & & \multicolumn{4}{|c|}{ Quadrant I } \\
\hline & Pure Cows & Cows with breed records & & & Pure Cows & Cows with breed records & \\
\hline & 15 & 35 & & & 30 & 23 & \\
\hline epp & $1134 \pm 44$ & $1178 \pm 33$ & $\mathrm{~ns}$ & epp & $1035 \pm 23$ & $1058 \pm 40$ & ns \\
\hline np & $3(2-6)$ & $3(1-7)$ & ns & np & $3(1-8)$ & $2(1-8)$ & ns \\
\hline pl 305 & $5516 \pm 208$ & $5281 \pm 124$ & $\mathrm{~ns}$ & pl 305 & $6858 \pm 141$ & $6729 \pm 121$ & ns \\
\hline GB & $651 \pm 60$ & $520 \pm 52$ & ns & GB & $858 \pm 74$ & $682 \pm 87$ & $\mathrm{~ns}$ \\
\hline il & $7,8 \pm 0,4$ & $6,5 \pm 0,4$ & ns & il & $9,6 \pm 0,3$ & $8,2 \pm 0,5$ & $*$ \\
\hline ipp & $458 \pm 18$ & $452 \pm 11$ & $\mathrm{~ns}$ & ipp & $533 \pm 17$ & $610 \pm 28$ & * \\
\hline ig & $0.261 \pm 0.01$ & $0.227 \pm 0.01$ & $\mathrm{~ns}$ & ig & $0.319 \pm 0.01$ & $0.280 \pm 0.01$ & $*$ \\
\hline pl total & $19704 \pm 1923$ & $17930 \pm 1814$ & $\mathrm{~ns}$ & pl total & $25640 \pm 2127$ & $20426 \pm 2846$ & $\mathrm{~ns}$ \\
\hline \multicolumn{3}{|c|}{ Quadrant III } & & \multicolumn{4}{|c|}{ Quadrant IV } \\
\hline & Pure Cows & Cows with breed records & & & Pure Cows & Cows with breed records & \\
\hline & 13 & 47 & & & 30 & 24 & \\
\hline epp & $850 \pm 36$ & $853 \pm 14$ & ns & epp & $853 \pm 22$ & $866 \pm 19$ & ns \\
\hline np & $3(1-6)$ & $4(1-7)$ & ns & np & $4(2-9)$ & $5(2-10)$ & ns \\
\hline pl 305 & $5059 \pm 173$ & $5247 \pm 102$ & ns & pl 305 & $6686 \pm 121$ & $6265 \pm 175$ & $*$ \\
\hline GB & $517 \pm 72$ & $628 \pm 42$ & ns & GB & $1177 \pm 71$ & $1233 \pm 84$ & ns \\
\hline il & $7.4 \pm 0.4$ & $7.8 \pm 0.3$ & ns & il & $11.5 \pm 0.4$ & $11.2 \pm 0.3$ & ns \\
\hline ipp & $452 \pm 29$ & $430 \pm 7$ & ns & ipp & $494 \pm 12$ & $479 \pm 13$ & $\mathrm{~ns}$ \\
\hline ig & $0.272 \pm 0.01$ & $0.264 \pm 0.01$ & $\mathrm{~ns}$ & ig & $0.398 \pm 0.01$ & $0.368 \pm 0.01$ & ns \\
\hline pl total & $14992 \pm 2132$ & $18804 \pm 1290$ & ns & pl total & $34160 \pm 2231$ & $37476 \pm 2527$ & $\mathrm{~ns}$ \\
\hline
\end{tabular}

Table 2. Productive and reproductive traits of pure cows and cows with breed records located in Quadrants I and IV

\begin{tabular}{|c|c|c|c|c|c|}
\hline \multirow[b]{2}{*}{ Type of cow } & \multirow[t]{2}{*}{ Trait } & \multicolumn{2}{|c|}{$\begin{array}{c}\text { Quadrant I } \\
(>\mathrm{CP1} \text { y > CP2 })\end{array}$} & \multicolumn{2}{|c|}{$\begin{array}{c}\text { Quadrant IV } \\
(<\mathrm{CP1} \text { y > CP2 })\end{array}$} \\
\hline & & VP & VRC & VP & VRC \\
\hline \multirow[t]{4}{*}{ Real data } & PL 305 (liters) & 6858 & 6729 & 6686 & 6265 \\
\hline & NP & 3 & 2 & 4 & 5 \\
\hline & IPP (days) & 533 & 610 & 494 & 479 \\
\hline & EPP (months) & 33 & 33 & 28 & 28 \\
\hline \multirow[t]{3}{*}{ Model to 100 cows } & PL total (liters) ${ }^{1}$ & 685800 & 672900 & 668600 & 626500 \\
\hline & Births $^{2}$ & 71 & 59 & 75 & 75 \\
\hline & Born Females $^{3}$ & 36 & 30 & 38 & 38 \\
\hline \multirow[t]{5}{*}{ Constant } & $\% \operatorname{loss}^{4}$ & 8 & 8 & 8 & 8 \\
\hline & Real females ${ }^{5}$ & 33 & 27 & 35 & 35 \\
\hline & Apt females ${ }^{6}$ & 21 & 17 & 29 & 29 \\
\hline & Replacement $^{7}$ & 33 & 50 & 25 & 20 \\
\hline & Replacement heifers ${ }^{8}$ & -12 & -33 & +4 & +9 \\
\hline \multirow[t]{4}{*}{ Income } & Milk $^{9}$ & 2948940 & 2893470 & 2874980 & 2693950 \\
\hline & Spent cows ${ }^{10}$ & 326700 & 495000 & 247500 & 198000 \\
\hline & Calf $^{11}$ & 98000 & 81200 & 103600 & 103600 \\
\hline & Heifer $^{12}$ & 0 & 0 & 100000 & 225000 \\
\hline Outflow $^{13}$ & Heifer & 300000 & 825000 & 0 & 0 \\
\hline Balance $^{14}$ & & 3073640 & 2644670 & 3326080 & 3220550 \\
\hline
\end{tabular}




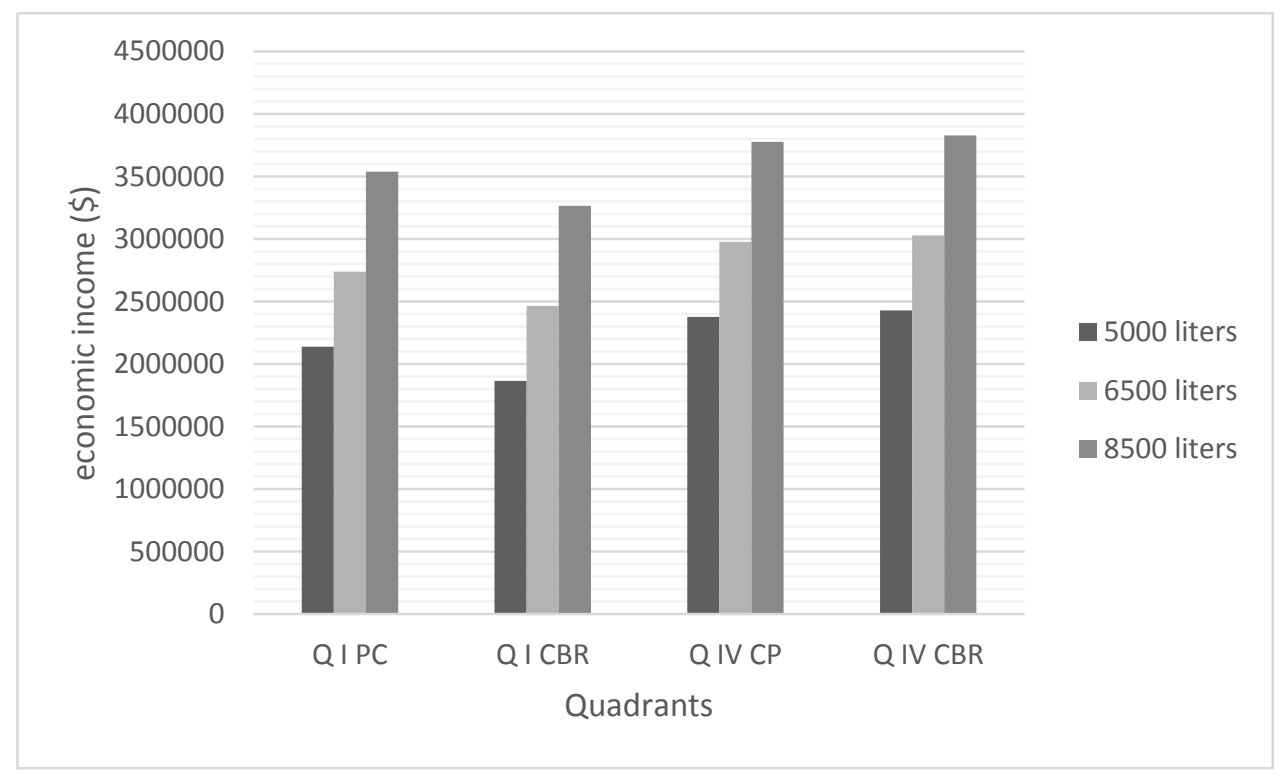

Figure 2. Relationship between milk production and economic income

Figure 2 describes the economic income corresponding to pure cows and those with breed records, located in Quadrants I and IV as regards three values of milk production: 5000, 6000 and 8500 liters. Logically, it is observed that as milk production increases, there is higher income both in QI as in QIV. However, independently from milk production, the combination of the higher efficiency in the rest of the variables involved (number of deliveries, delivery - delivery interval and age at first delivery), determines higher incomes from cows in QIV.

\section{Discussion}

Even though animal health and welfare together with sustainability and the minimum use of supplies are nowadays founding factors for milk production; for the last decades, the main objectives pursued when breeding milking cows have been maximizing the efficiency of milk per cow and the early maturity in heifers (Horn et al., 2012). It can be seen in Figure 1 that cows belonging to Quadrant I present a high milk production as well as kilograms of GB, higher rates of milk and GB, but also lower life expectancy, higher age at delivery, and a longer delivery-delivery interval. Cows in Quadrants II and III show quite similar results, except for age at first delivery, which is higher in cows of Quadrant II. As for the rest of the indicators, they are cows with low life-expectancy, low IL and IG, with lower milk production per lactation, but a shorter delivery-delivery interval. Cows in Quadrant IV are those with the longest life-expectancy, the higher IL and IG, with a production level similar to those in Quadrant I but with a shorter delivery-delivery interval than these. There are no big differences as regards the predominance of pure cows or cows with breed records between Quadrants I and IV. The difference observed in terms of income lies in that cows of one or the other category belonging to Quadrant IV show a longer life expectancy combined with milk production (6000-6500 liters) according to the nutritional and environmental conditions of the grazing system. These conditions allows animals to produce without affecting their reproductive efficiency; which lets them reach higher rates of milk and fat, showing their adaptation to this particular productive system.

Cows in Quadrant I would represent those from intensive systems (higher milk production) while cows in Quadrant IV would be examples of those adapted to grazing systems (higher lifetime). The key factor for these cows, independently from their group (pure or with breed records), is their lifetime expectancy. In the last 25 years, the average number of deliveries in specialized breed has fallen from 3.5 to about 3.0 (Knaus, 2009). In evolutionary terms, life expectancy is correlated with a higher opportunity of reproduction and therefore a higher biological effectiveness, that is to say a higher biological efficiency. Cows in Quadrant IV are an example in this sense since, in comparative terms, they present longer life expectancy, get pregnant sooner (lower age at first delivery), expressed higher values of IL and IG and, even though they are not those with the highest adjusted production, they produce the higher quantity of GB with delivery-delivery intervals not so far from the optimun from Quadrant I. They are cows "for extensive grazing systems" which show reproductive imbalance due mainly to the handling and nutritional conditions. The model presented in Chart 1 considers all the cow's productive life 
and shows that the higher incomes come from those located in Quadrant IV despite the fact that they are -in comparison- those with the lowest production; but this is so due to their long life span (higher number of deliveries), better reproductive efficiency (shorter delivery-delivery interval) and younger age at first delivery. Part of this revenue advantage in longevity lies in retaining productive cows for a longer period of time, ensuring that less productive cows are replaced as soon as economically possible. Therefore, in this context, the potential productive life rather than the average productive life of dairy cows become important. The proportion of forced (involuntary) slaughter governs the potential productive life and, therefore, the economic advantage of longevity (Stott, 1994). This reveals the role of those traits, which were not taken into account in pre-established economic calculations (where income is only shown by means of milk sale). The higher percentage of income comes through milk sale, but there is still a $15 \%$ of the total income that may come from selling the surplus heifers, male calves and spent cows, which -despite not having a big influence in the total income- are worth to be considered. These results are in agreement with previous reports (Marini and Oyarzabal, 2002b), showing that higher milk production would not be enough in order to guarantee higher incomes (Chart 1 and Figure 2), but the economic balance in the different groups under analysis indicate that the global productive efficiency is related not only to milk production but also to the behavior of other traits related to the reproductive and lifetime circle, that is to say, with the adaptation to the particular conditions of the grazing system (allowing the use of lower quantities of concentrated and conserved forages, while keeping the production). In addition, these results agree with those found by Horn et al., (2012) where a reduction in the performance of milk production does not necessarily mean lower incomes, if it coincides with a longer lifetime span. The economic advantage of a longer lifetime lies mainly in the fact of keeping productive cows as long as possible, while making sure the less productive cows are replaced as soon as it is economical to carry out. By reducing involuntary sacrifice, the costs of replacement are reduced and production increases due to a lower frequency of cows with low performance and a longer lifetime of cows with high performance (Rogers et al., 1988).

\section{Conclusion}

It is concluded that the economic efficiency of the two groups of Holstein cows under analysis is not only determined by milk production, but also for other traits such as lifetime and reproduction.

\section{References}

Bargo, F. (2016). Technological and sectorial prospective analyzes. Technological projection to 2025 of the dairy complex. Secretary of Planning and Policies. Ministry of Science and Technology and Productive Innovation, $\mathrm{pp} 34$.

Camargo, O. (2012). Milking cows between economic efficiency and biological inefficiency. Arch. Zootec. 61, 13-29.

Ferrada, N. S. (2004). Determining the economic result of milk production. In: Techniques for milk production, meadows and management for Argentinian familiar farming (AFC), pp 95.

Galli, J., Planisich, A., Madelón, E., Larripa, M., \& Nalino, M. (2016). To a sustainable development of milking farms in the South Cooperative Dairy Farms. AGROMENSAJES, 46, 14-23.

González, B. A. V. (2010). Eficiencia en recría de vaquillonas en establecimientos lecheros [en línea]. Trabajo Final. Facultad de Ciencias Agrarias, Universidad Católica Argentina. Disponible en: http://bibliotecadigital.uca.edu.ar/repositorio/tesis/eficiencia-recria-vaquillonas-establecimientos-lecheros.p df In Spanish

Horn, M., Knaus, W., Kirner, L., \& Steinwidder, A. (2012). Economic Evaluation of Longevity in Organic Dairy Farming. Org. Agr., 2, 127-143. https://doi.org/10.1007/s13165-012-0027-6

Knaus, W. (2009). Dairy cows trapped between performance demands and adaptability. J Sci Food Agric, 89, 1107-1114. https://doi.org/10.1002/jsfa.3575

Magnasco, R. P. (1998). How to evaluate reproductive efficiency. Produce XXI. 7(83), 45-52.

Marini, P. R., \& Oyarzabal, M. I. (2002b). Production patterns in milking cows. 2. Description of average cows and estimation of income through categories of production. Rev. Arg. Prod. Anim., 22(1), 47-60.

Marini, P. R. (2016). Biological efficiency in the dairy cow. Post Doctorate thesis. National University of Rosario, pp81.

Pace Guerrero, I. R., \& Gastaldi, L. B. (2016). Estimating economic efficiency in the pampean milking systems. INTA, $\mathrm{pp} 23$. 
Rogers, G. W., Van Arendonk, J. A. M., \& McDaniel, B. T. (1988). Influence of Involuntary Cullin on Optimum Culling Rates and Annualised Net Revenue, Journal of Dairy Science, 71, 3463-3469. https://doi.org/10.3168/jds.S0022-0302(88)79952-X

Sanchez, C., Suero, M., Castignani, H., Teran, J., \& Marino, M. (2012). Milking in Argentina: present situation and evolution (2008 a 2011). Trabajo presentado la Reunión Anual de la Asociación Argentina de Economía Agraria.

Stott, A. W. (1994). The economic advantage of longevity in the dairy cow. Journal of Agricultural Economics, 45(1), 113-122. https://doi.org/10.1111/j.1477-9552.1994.tb00382.x

\section{Copyrights}

Copyright for this article is retained by the author(s), with first publication rights granted to the journal.

This is an open-access article distributed under the terms and conditions of the Creative Commons Attribution license (http://creativecommons.org/licenses/by/3.0/). 